\title{
High-Efficiently Photoelectrochemical Hydrogen Production over Zn-Incorporated $\mathrm{TiO}_{2}$ Nanotubes
}

\author{
Gayoung Lee, ${ }^{1}$ Min-Kyeong Yeo, ${ }^{2}$ Myeong-Heon Um, ${ }^{3}$ and Misook Kang ${ }^{1}$ \\ ${ }^{1}$ Department of Chemistry, College of Science, Yeungnam University, Gyeongsan, Gyeongbuk 712-749, Republic of Korea \\ ${ }^{2}$ Department of Environmental Science and Environmental Research, College of Engineering, Kyung Hee University, Yongin, \\ Gyeonggi 446-701, Republic of Korea \\ ${ }^{3}$ Department of Chemical Engineering, College of Engineering, Kongju National University, Cheonan, \\ Chungnam 330-717, Republic of Korea
}

Correspondence should be addressed to Misook Kang, mskang@ynu.ac.kr

Received 3 February 2012; Revised 21 March 2012; Accepted 22 March 2012

Academic Editor: Baibiao Huang

Copyright ( $) 2012$ Gayoung Lee et al. This is an open access article distributed under the Creative Commons Attribution License, which permits unrestricted use, distribution, and reproduction in any medium, provided the original work is properly cited.

To investigate the $\mathrm{Zn}$ dopant and nanotube morphology effects of $\mathrm{TiO}_{2}$ in electrochemical hydrogen production from the photosplitting of methanol/water solution, we have designed a $\mathrm{Zn}$-incorporated $\mathrm{TiO}_{2}$ nanotube $(\mathrm{Zn}-\mathrm{TNT})$ photocatalyst. The TNT and Zn-TNT materials had a width of $70 \sim 100 \mathrm{~nm}$. The hydrogen production over the Zn-TNT photocatalysts was higher than that over the TNT; specifically, $10.2 \mathrm{~mL}$ of $\mathrm{H}_{2}$ gas was produced after 9 hours when $0.5 \mathrm{~g}$ of $0.01 \mathrm{~mol} \% \mathrm{Zn}$-TNT was used. The zeta-potential values in aqueous solution determined by electrophoretic light scattering (ELS) had negative surface charges, which was related to the surface stability, and the absolute value was the largest in $0.01 \mathrm{~mol} \% \mathrm{Zn}$-TNT. On the basis of UV-visible and photoluminescence (PL) spectra results, the high photoactivity of Zn-TNT was attributed to the shift toward the visible region and increase of PL intensity due to the increased number of excited electrons and holes.

\section{Introduction}

Hydrogen is likely to become an increasingly used energy source due to its environmental friendliness. Therefore, the technology for generating hydrogen by the photosplitting of water using a photocatalyst has attracted considerable research attention. The photocatalytic formation of hydrogen and oxygen on semiconductors such as $\mathrm{TiO}_{2}[1-5]$ and $\mathrm{MTiO}_{3}$ [6-10] has been studied extensively due to the low bandgap and high corrosion resistance of these semiconductor materials. However, the photocatalytic decomposition of water on a $\mathrm{TiO}_{2}$ photocatalyst is ineffective because the amount of hydrogen produced is limited by the rapid recombination of holes and electrons, resulting in the formation of water. In order to overcome this rapid recombination, the noble metals ( $\mathrm{Ag}, \mathrm{Pd}, \mathrm{Pt}$, and $\mathrm{Ga}$ ) loaded $\mathrm{TiO}_{2}$ photocatalysts [11-14] have used in methanol or ethanol photodecomposition, rather than water which has relatively high activity and chemical stability under UV irradiation. However, the hydrogen production remains uneconomically low, and noble metals are too expensive. Therefore, new and inexpensive photocatalysts need to be developed that are environmentally friendly and possess greater hydrogen-producing activity under visible light irradiation.

Nanotubes materials have recently been applied on photocatalysis [15-17]. Xu et al. [15] reported an efficient $\mathrm{Cu}-$ incorporated $\mathrm{TiO}_{2}$ nanotube (Cu-TNT) photocatalyst for $\mathrm{H}_{2}$ production, with an average $\mathrm{H}_{2}$ generation rate recorded across a 4-hour reaction of between 15.7 and $40.2 \mathrm{mmol} \mathrm{h}^{-1} \mathrm{~g}^{-1}$ catalyst, depending on the initial $\mathrm{Cu} / \mathrm{Ti}$ ratio in the solution, which was optimized at 10 atom\%. Sang et al. [16] have also researched the photoelectrochemical hydrogen evolving over C- and N-doped TNT arrays electrode: C-TNT could harvest more light and produce more photoactive sites than N-TNT, which also made the charge transfer resistance in C-TNT larger than that in N-TNT. As the result, under UV-vis light irradiation, the average hydrogen generation rate of C-TNT was $282 \mu \mathrm{L} \mathrm{h}^{-1} \mathrm{~cm}^{-2}$. 
However, little research has been conducted on metal-TNT, and the correlation between TNT properties and hydrogenation performance has barely been addressed.

In this study, Zn-incorporated TNT (Zn-TNT) was synthesized using $\mathrm{Zn}-\mathrm{TiO}_{2}$ nanosized particles as starting materials with three molar ratios of $\mathrm{Ti} / \mathrm{Zn}$. The relationship between the spectroscopic properties of the nanotube particles and the photocatalytic performance for the production of $\mathrm{H}_{2}$ was examined by X-ray diffraction (XRD), transmission electron microscopy (TEM), UV-visible spectroscopy, photoluminescence (PL), electrophoretic light scattering (ELS), and cyclic voltammetry (CV).

\section{Experimental}

To synthesize the TNT and Zn-TNT, all the nanosized particles of $\mathrm{TiO}_{2}$ and $\mathrm{Zn}$-incorporated $\mathrm{TiO}_{2}$ were prepared using a hydrothermal treatment as shown in Figure 1(a). First, the nanometer-sized $\mathrm{TiO}_{2}$ and $\mathrm{Zn}-\mathrm{TiO}_{2}$ with various mol fractions of zinc $(0.1,0.01$, and $0.001 \mathrm{~mol}-\%)$ were prepared using a solvothermal treatment: titanium tetraisopropoxide (TTIP, 99.95\%, Junsei Chemical, Japan) and zinc acetate $\left(\mathrm{Zn}\left(\mathrm{CH}_{3} \mathrm{COO}\right)_{2} \cdot 2 \mathrm{H}_{2} \mathrm{O}\right.$, 99.99\%, Junsei Chemical, Japan) were used as the titanium and zinc precursors, respectively, and ethanol was used as the solvent. After 0.1, 0.01, and $0.001 \mathrm{~mol}-\%$ of zinc acetate and $1.0 \mathrm{~mol}$ TTIP were added stepwise to $250 \mathrm{~mL}$ of ethanol, the mixture was stirred homogeneously for $2 \mathrm{~h}$. Acetic acid was added and the $\mathrm{pH}$ was maintained at 4.0 for rapid hydrolysis. The final solution was stirred homogeneously for $2 \mathrm{~h}$ and moved to an autoclave for thermal treatment. TTIP and zinc acetate were hydrolyzed during thermal treatment at $200^{\circ} \mathrm{C}$ for $8 \mathrm{~h}$ under a nitrogen environment with a pressure of approximately $15.0 \mathrm{~atm}$. The resulting precipitate was washed with distilled water until the $\mathrm{pH}$ was neutralized at 7.0 and then dried at $80^{\circ} \mathrm{C}$ for $24 \mathrm{~h}$. Next, the general preparation methods of TNT and Zn-TNT powders have been described in the literature [18]. Prepared $\mathrm{TiO}_{2}$ or $\mathrm{Zn}-\mathrm{TiO}_{2}$ particles were added in $10.0 \mathrm{M} \mathrm{NaOH}$ aqueous solution (Figure $1(\mathrm{~b})$ ), and the mixture was stirred homogeneously for $2 \mathrm{~h}$ and moved to an autoclave for thermal treatment at $130^{\circ} \mathrm{C}$ for $24 \mathrm{~h}$ The resulting precipitate was washed with $\mathrm{HCl}$ solution until the $\mathrm{pH}=7.0$ and then dried at $80^{\circ} \mathrm{C}$ for $24 \mathrm{~h}$. The TNT or ZnTNT was in the form of multiwalled scroll nanotubes with an average width of about 70-100 nm.

The synthesized powders were examined by XRD (MPD, PANalytical) with nickel-filtered $\mathrm{CuK} \alpha$ radiation $(30 \mathrm{kV}$, $30 \mathrm{~mA}$ ). The sizes and shapes of the TNT and Zn-TNT were measured by a transmission electron microscope (TEM; H7600, Hitachi) operated at $120 \mathrm{kV}$. UV-visible spectra were obtained using a Cary500Scan (Varian) spectrometer with a reflectance sphere in the range of $200 \sim 800 \mathrm{~nm}$. PL spectroscopy measurements were obtained using a LabRamHR (Jobin Yvon) spectrometer in the range of $200 \sim 700 \mathrm{~nm}$ to examine the number of photoexcited electron hole pairs for all of the samples. The specific surface area was calculated according to the Brunauer-Emmett-Teller (BET) theory that gives the isotherm equation for multilayer adsorption by generalization of Langmuir's treatment of the unimolecular layer. The BET surface area was measured using a Belsorp II-mini (BEL, Japan inc.) equipped with a TCD instrument. The CV results were obtained using a BAS 100B instrument at room temperature and a scan rate of $100 \mathrm{mV} / \mathrm{s}$ with $0.1 \mathrm{M} \mathrm{KCl}$ as the supporting electrolyte, platinum wires as the working and counter electrodes, and $\mathrm{Ag} / \mathrm{AgCl}$ as the reference electrode. Zeta potentials of the TNT and ZnTNT were determined by electrophoretic mobility using an electrophoresis measurement apparatus (ELS 8000, Otsuka Electronics, Japan) with a plate sample cell. ELS determinations were performed with the reference beam mode and a laser light source wavelength of $670 \mathrm{~nm}$, modular frequency of $250 \mathrm{~Hz}$, and scattering angle of $15^{\circ}$. The standard error of the zeta potentials, converted from the experimentally determined electrophoretic mobility according to the Smoluchowsk [19] limit of the Henry equation, was typically $<1.5 \%$ and the percent error $<5 \%$. To measure the zeta potentials, $0.1 \mathrm{wt} \%$ of each sample was dispersed in deionized water and the solution $\mathrm{pH}$ was adjusted with $\mathrm{HCl}$ or $\mathrm{NaOH}$. The relative molecular diameter size distributions of the various solutions were also measured by this equipment. The zeta potential distributions were obtained by averaging 2 or 3 runs.

The photosplitting of methanol/water was carried out using a liquid photoreactor designed in our laboratory. For water photosplitting, $0.5 \mathrm{~g}$ of the powdered TNT and ZnTNT photocatalysts was added to $1.0-\mathrm{L}$ of distilled water in a 2.0-L Pyrex reactor. UV-lamps $\left(6 \times 3 \mathrm{~W} \mathrm{~cm}^{-2}=18 \mathrm{~W} \mathrm{~cm}^{-2}\right.$, $30 \mathrm{~cm}$ length $\times 2.0 \mathrm{~cm}$ diameter; Shinan, Korea) emitting radiation at $365 \mathrm{~nm}$ were used. Water photosplitting was carried out for $9 \mathrm{~h}$ with constant stirring. Hydrogen evolution was measured after $1 \mathrm{~h}$. The hydrogen gas $\left(\mathrm{H}_{2}\right)$ produced during water photosplitting was analyzed using a TCD-type gas chromatograph (GC, model DS 6200; Donam Instruments Inc., Korea). To determine the products and intermediates, the GC was connected directly to the water decomposition reactor under the following GC conditions: TCD detector, Carbosphere column (Alltech, Deerfield, IL), $413 \mathrm{~K}$ injection temp., $393 \mathrm{~K}$ initial temp., $393 \mathrm{~K}$ final temp., and $423 \mathrm{~K}$ detector temp.

\section{Results and Discussion}

Figures 2(a) and 2(b) show the XRD patterns of the $\mathrm{Zn}$ $\mathrm{TiO}_{2}$ nanoparticles (Zn-TNP) and $\mathrm{Zn}$-TNT. The anatase structure in both TNP and TNT without Zn element had main peaks at $24-25.3,38.0,48.2,54,63$, and $68^{\circ} 2 \theta$, which were assigned to the $\left(\mathrm{d}_{101}\right),\left(\mathrm{d}_{004}\right),\left(\mathrm{d}_{200}\right),\left(\mathrm{d}_{105}\right),\left(\mathrm{d}_{211}\right)$, and $\left(d_{204}\right)$ planes, respectively $[20,21]$. The peak intensities of the anatase structures were decreased and slightly shifted to high angles with increasing $\mathrm{Zn}$ content. Two special peaks (JSPDF\#251164), which were assigned to $\mathrm{Zn}_{2} \mathrm{TiO}_{4}$ at $2 \theta=28.5\left(\mathrm{~d}_{220}\right)$ and $34.5\left(\mathrm{~d}_{311}\right)$ in $0.1 \mathrm{~mol} \% \mathrm{Zn}-\mathrm{TNP}$ and $\mathrm{Zn}$-TNTs, were attributed to the good connection between $\mathrm{Zn}$ and the $\mathrm{TiO}_{2}$ framework. Following a literature [18], an $\mathrm{H}_{2} \mathrm{Ti}_{2} \mathrm{O}_{5}\left(\mathrm{~d}_{003}\right.$, JSPDF\#360654) peak also appears at same location to $28 \sim 29^{\circ}$ of $\mathrm{Zn}_{2} \mathrm{TiO}_{4}$ in TNT and $\mathrm{Zn}$-TNT because 


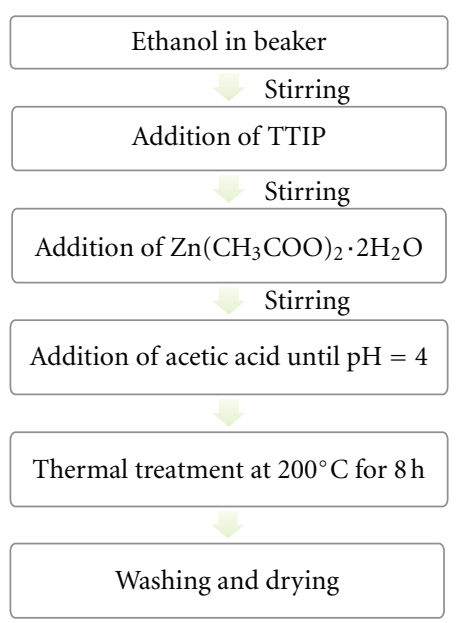

(a)

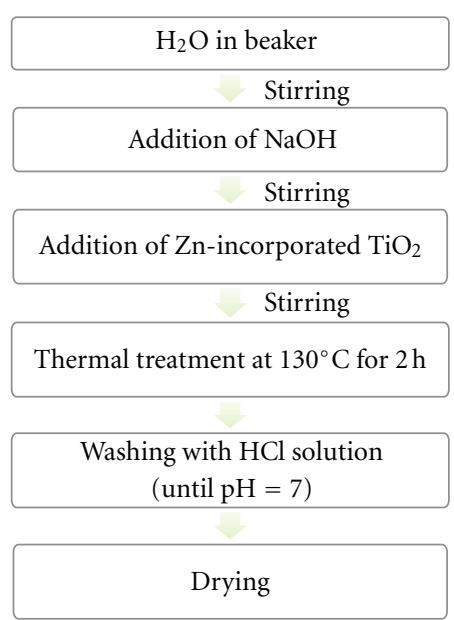

(b)

FIGURE 1: Synthesis procedure of (a) the $\mathrm{Zn}$-incorporated $\mathrm{TiO}_{2}$ nanoparticles $(\mathrm{Zn}-\mathrm{TNP})$ and (b) the $\mathrm{Zn}$-incorporated $\mathrm{TiO} \mathrm{O}_{2}$ nanotubes $(\mathrm{Zn}$ TNT).

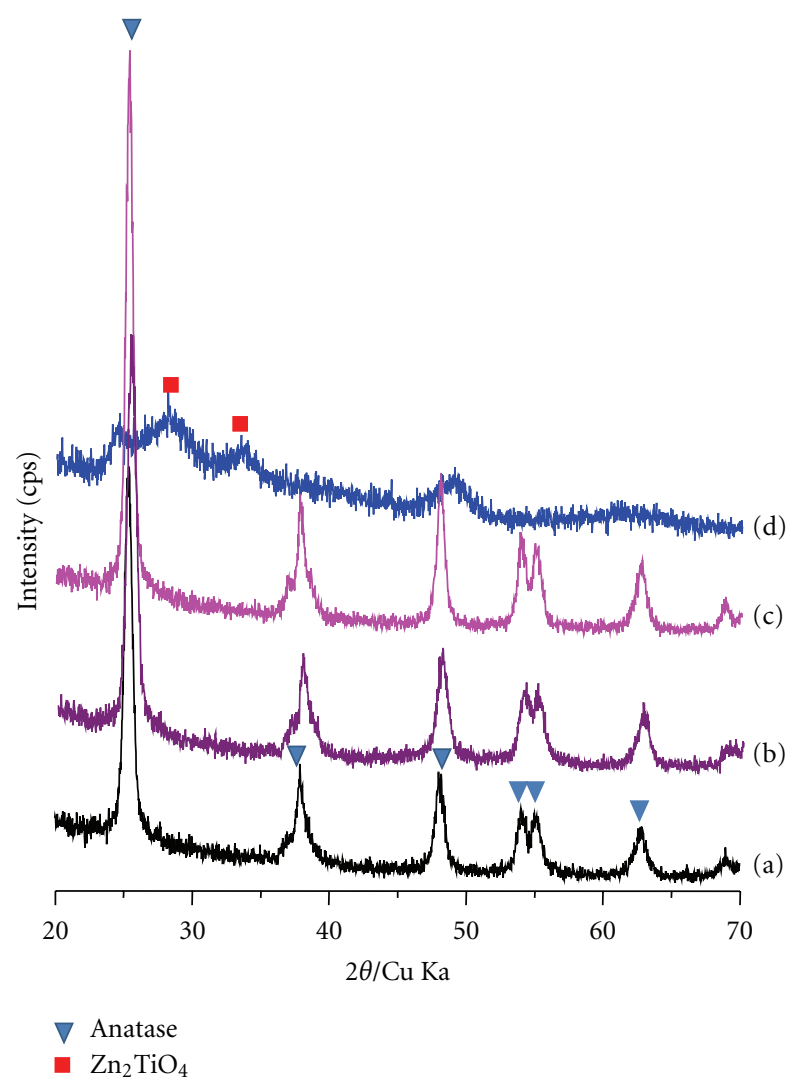

(a)

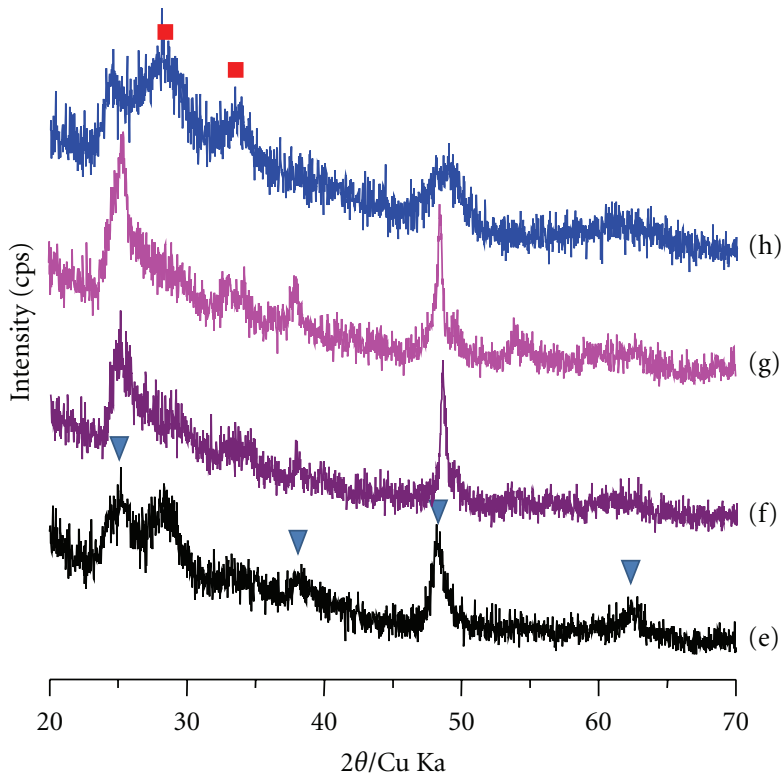

$\nabla$ Anatase

- $\mathrm{Zn}_{2} \mathrm{TiO}_{4}$

Figure 2: XRD patterns of synthesized Zn-TNP (a) and Zn-TNT (b): (a) TNP, (b) $0.001 \mathrm{~mol} \% \mathrm{Zn}-\mathrm{TNP}$, (c) $0.01 \mathrm{~mol} \% \mathrm{Zn}-\mathrm{TNP}$, (d) $0.1 \mathrm{~mol} \%$ TNP, (e) TNT,(f) $0.001 \mathrm{~mol} \%$ Zn-TNT, (g) $0.01 \mathrm{~mol} \% \mathrm{Zn}-\mathrm{TNT}$, and (h) $0.1 \mathrm{~mol} \% \mathrm{Zn}-\mathrm{TNT}$.

treating $\mathrm{TiO}_{2}$ or $\mathrm{Zn}-\mathrm{TiO}_{2}$ with concentrated $\mathrm{NaOH}$ solution preferentially ruptured the longer $\mathrm{Ti}-\mathrm{O}$ bonds due to the action of the $\mathrm{OH}^{-}$ions. Linear fragments were formed and linked together by $\mathrm{O}^{-}-\mathrm{Na}^{+}-\mathrm{O}^{-}$ionic bonds to form planar fragments that peeled off from the $\mathrm{TiO}_{2}$ crystalline particles. The $(-\mathrm{Ti}-\mathrm{O}-\mathrm{Ti}-\mathrm{O}-\mathrm{Ti}-\mathrm{O}-)_{x}$ chains included in the planar fragments were rendered flexible by the covalent link between their end groups, so that they formed a thermodynamically stable product, that is, solid nanotube $\mathrm{Na}_{2} \mathrm{Ti}_{2} \mathrm{O}_{4}(\mathrm{OH})_{2}$, indicating that the monolayer nanotube 


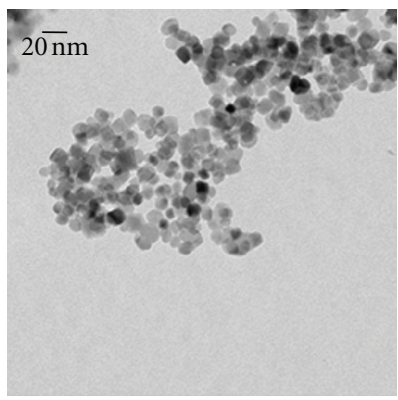

(a)

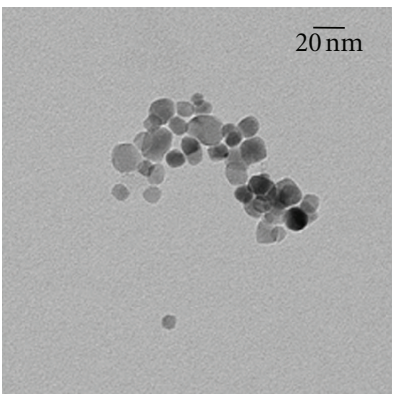

(e)

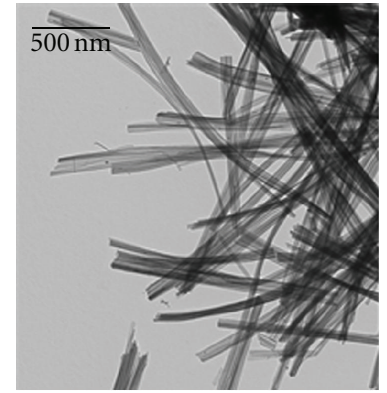

(b)

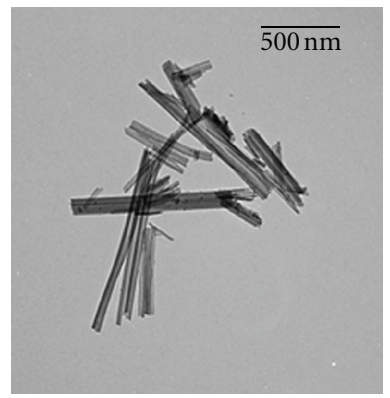

(f)

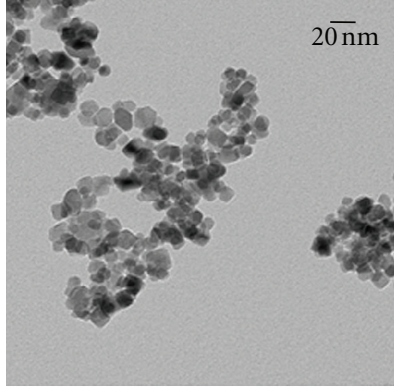

(c)

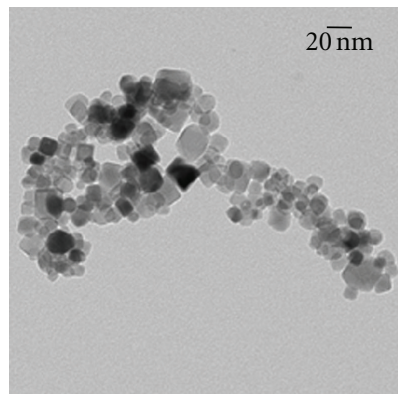

(g)

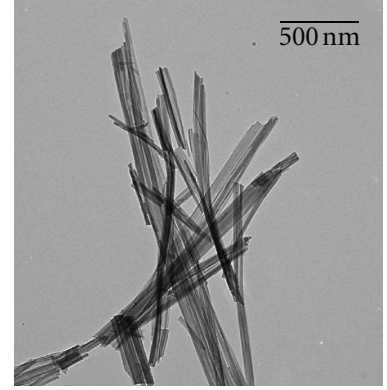

(d)

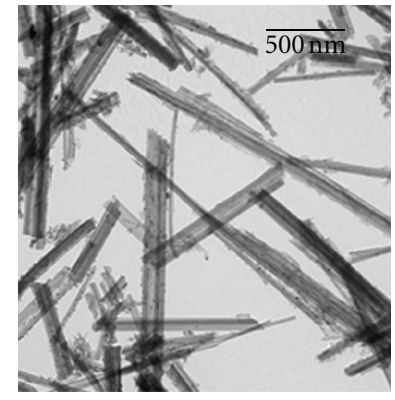

(h)

Figure 3: TEM images of synthesized Zn-TNP and Zn-TNT: (a) TNP, (b) TNT, (c) 0.001 mol\% Zn-TNP, (d) 0.001 mol\% Zn-TNT, (e) $0.01 \mathrm{~mol} \%$ Zn-TNP, (f) $0.01 \mathrm{~mol} \% \mathrm{Zn}-\mathrm{TNT}$, (g) $0.1 \mathrm{~mol} \% \mathrm{Zn}-\mathrm{TNP}$, and (h) $0.1 \mathrm{~mol} \% \mathrm{Zn}-\mathrm{TNT}$.

may have acted as the template for the multilayer nanotubes. Such a formation process of nanotube $\mathrm{Na}_{2} \mathrm{Ti}_{2} \mathrm{O}_{4}(\mathrm{OH})_{2}$ was evident. After replacing $\mathrm{Na}^{+}$with $\mathrm{H}^{+}$using $\mathrm{HCl}$ solution at $\mathrm{pH}$ 1, the nanotube $\mathrm{H}_{2} \mathrm{Ti}_{2} \mathrm{O}_{5}$ finally appeared due to the water elimination.

TEM images (Figure 3) show the particle shape of the TNP and Zn-TNP, and the pore shape and size of the TNT and Zn-TNT. TNP exhibited a mixture of rhombic and spherical particles of size distribution within the range of 5$10 \mathrm{~nm}$, and increasing size and cubic shape as the $\mathrm{Zn}$ content was increased. The tube pore dimensions observed by TEM were a width of about $70-100 \mathrm{~nm}$, otherwise, the tube widths were wide corresponds of $\mathrm{Zn}$ addition.

Figures 4(a)-4(d) show the adsorption-desorption isotherms of $\mathrm{N}_{2}$ at $77 \mathrm{~K}$ for TNT and the three Zn-TNT samples. The figure illustrates the shape and behavior of the $\mathrm{N}_{2}$ adsorption isotherms for nonporous and nanotube materials. All the isotherms belong to IV types in the IUPAC classification [22]: the isotherm has been widely used, and a certain hysteresis slope can be observed at intermediate and high relative pressures in TNT, which is indicative of the presence of large nanopores (tubes) (type IV in the IUPAC classification). The adsorption and desorption lines for TNT and Zn-TNT overlapped completely in the low relative pressure range, while the hysteresis loop was in the high relative pressure region $\left(P / P_{0}>0.4\right)$, mainly due to the presence of ink-bottle pore types that have a larger pore size in the bottle body, which induces hysteresis in the high relative pressure region $[22,23]$. The BET surface areas of $\mathrm{Zn}$-TNT were increased with increasing $\mathrm{Zn}$ content, although the total pore volume did not show any consistent trend. The pore size distribution (PDS) is an important characteristic for porous materials. Among the various methods that have been reported by researchers to identify the PDS of porous materials, $\mathrm{BJH}$ and Comparison Plots $[24,25]$ are the most suitable for the range of nanopores. The relative pressure at which pore filling takes place by capillary condensation can be calculated from Kelvin's equation [26], according to which the pore radius in which the capillary condensation occurs actively can be determined as a function of the relative pressure $\left(P / P_{0}\right)$. The mean pore diameter, $D_{p}$, was calculated from $D_{p}=4 V_{T} / S$, where $V_{T}$ is the total volume of pores, and $S$ the BET surface area. This was shown by the variation in the average pore diameter value, $D_{p}$, between 7.66 and $15.58 \mathrm{~nm}$ (Table 1).

Figure 5(b) summarizes the evolution of $\mathrm{H}_{2}$ from methanol/water photosplitting over the TNT and Zn-TNT photocatalysts in a batch-type, liquid photoreactor system (Figure 5(a)). A very small amount of $\mathrm{H}_{2}$ was collected over TNT after methanol/water photodecomposition for $9 \mathrm{~h}$, while a significant amount of $\mathrm{H}_{2}$ gas was collected over Zn-TNT. The amount of $\mathrm{H}_{2}$ produced reached $10.2 \mathrm{~mL}$ over $0.5 \mathrm{~g}$ of $0.01 \mathrm{~mol} \% \mathrm{Zn}$-TNT, and consequently the emitted rate for hydrogen production was $0.225 \mathrm{mmol} \mathrm{h}^{-1} \mathrm{~g}^{-1}$ in $0.01 \mathrm{~mol} \%$ Zn-TNT photocatalytic system. This result is significant compared to the results that $120 \sim 281 \mu \mathrm{Lh}^{-1}$ of hydrogen gases were produced over $\mathrm{H}-, \mathrm{N}$-, and C-TNT photocatalysts in reports by Sang et al. [16, 17]. While the amount produced was lower on the $0.1 \mathrm{~mol} \% \mathrm{Zn}$-TNT catalysts with higher loadings, possibly because of the structural damage. The use of two semiconductors, $\mathrm{Zn}$ and Ti oxides, with different redox energy levels, in contact, can be considered 


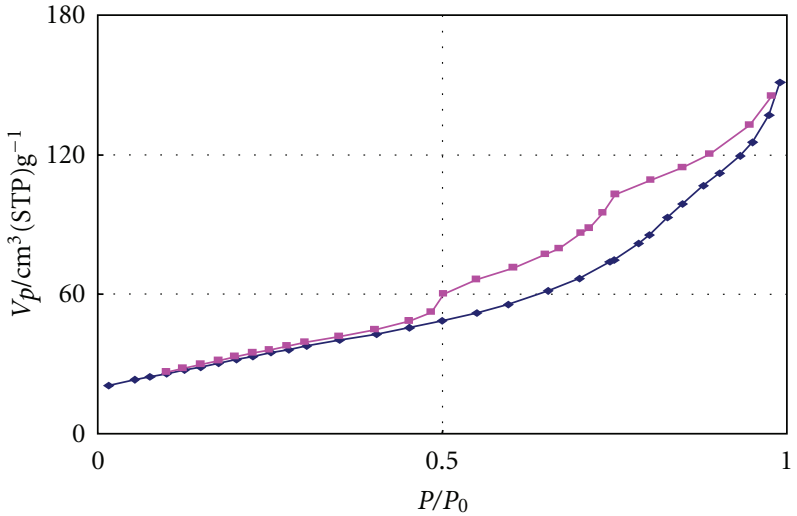

$\rightarrow$ ADS

$=$ DES

(a)

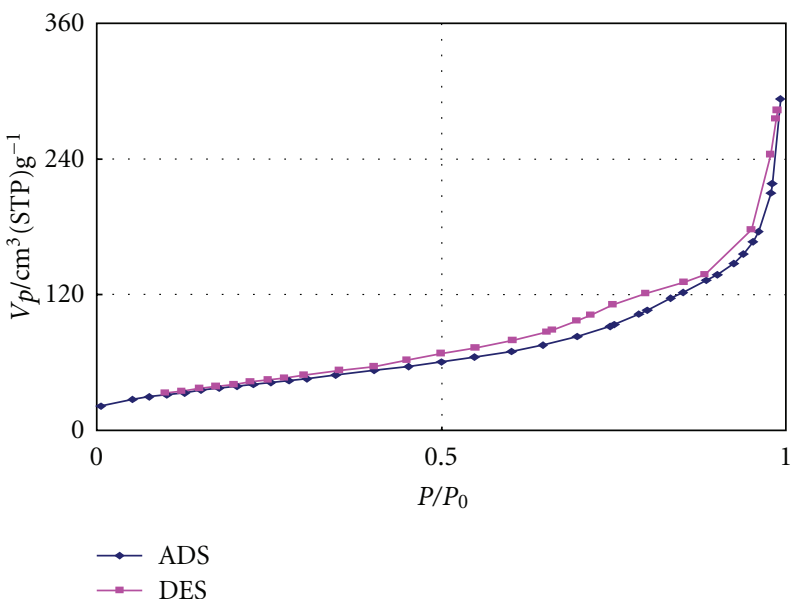

(c)

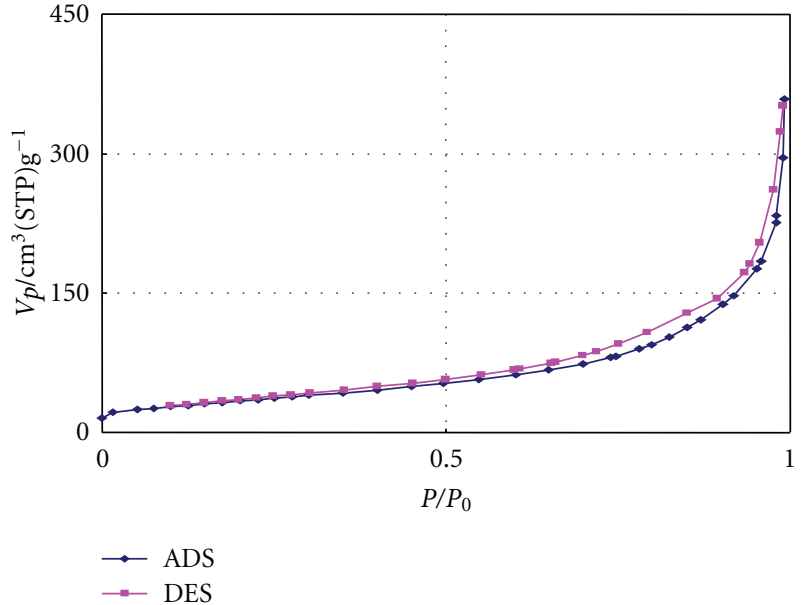

(b)

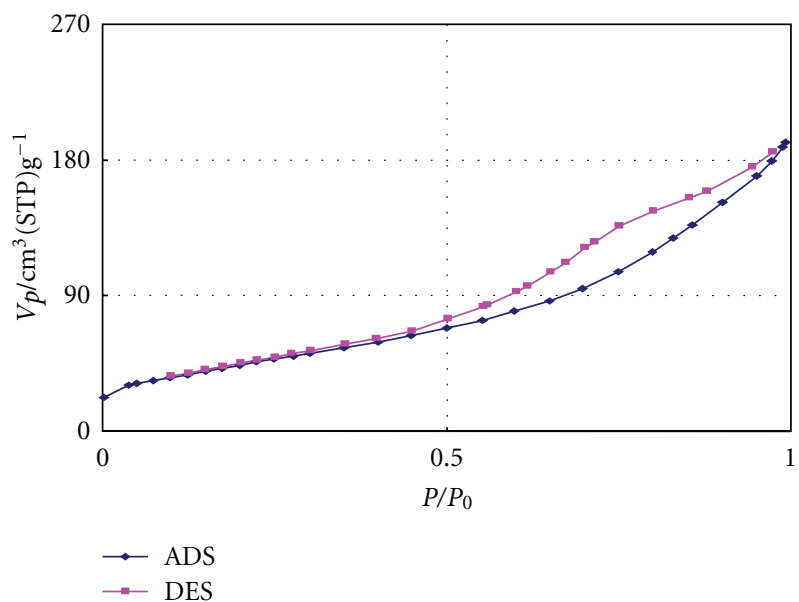

(d)

Figure 4: Adsorption-desorption isotherms of $\mathrm{N}_{2}$ at $77 \mathrm{~K}$ for TNT and Zn-TNT: (a) TNT, (b) $0.001 \mathrm{~mol} \% \mathrm{Zn}$-TNT, (c) $0.01 \mathrm{~mol} \% \mathrm{Zn}$-TNT, and (d) $0.1 \mathrm{~mol} \% \mathrm{Zn}$-TNT.

TABLE 1: Surface areas and average pore-diameter for TNT and Zn-TNT calculated by BET method.

\begin{tabular}{lccc}
\hline & $\begin{array}{c}\text { BET multipoint surface } \\
\text { area }\left[\mathrm{m}^{2} \mathrm{~g}^{-1}\right]\end{array}$ & $\begin{array}{c}\text { Total pore volume } \\
\left(P / P_{0}=0.990\right)\left[\mathrm{cm}^{3} \mathrm{~g}^{-1}\right]\end{array}$ & $\begin{array}{c}\text { Average pore diameter } \\
{[\mathrm{nm}]}\end{array}$ \\
\hline TNT & 104.21 & 0.2325 & 8.9262 \\
$0.001 \mathrm{~mol} \%$ Zn-TNT & 118.21 & 0.4605 & 15.583 \\
$0.01 \mathrm{~mol} \%$ Zn-TNT & 135.71 & 0.428 & 12.615 \\
$0.1 \mathrm{~mol} \%$ Zn-TNT & 153.01 & 0.293 & 7.66 \\
\hline
\end{tabular}

a promising method to improve charge separation and increase the lifetime of the charge carriers. Consequently, it enhances the efficiency of the interfacial charge transfer to the adsorbed substrate. For efficient inter-particle electron transfer between the semiconductor, which is considered the $\mathrm{ZnO}$ and TNT, the conduction band of TNT must be more anodic than the corresponding band of the $\mathrm{ZnO}$. Under visible irradiation, only the $\mathrm{ZnO}$ is excited, and electrons generated to their conduction band are injected into the inactivated TNT conduction band. If the valance band of the $\mathrm{ZnO}$ is more cathodic than that of TNT, the holes generated in the semiconductor remain there and cannot migrate to TNT. These thermodynamic conditions favor electron injection. Additionally, the tube-shaped TNT offers a larger surface area, and with the increasing affinity of methanol, the performance degradation is eventually considered to be higher.

Tables 2 and 3 and Figure 6 depict the influence of $\mathrm{pH}$ on the position of the zeta potential distribution median of TNT and Zn-TNT. The zeta potential of TNT suspension was significantly decreased with increasing $\mathrm{pH}$. The surface charges were transferred from positive in acidic solution 


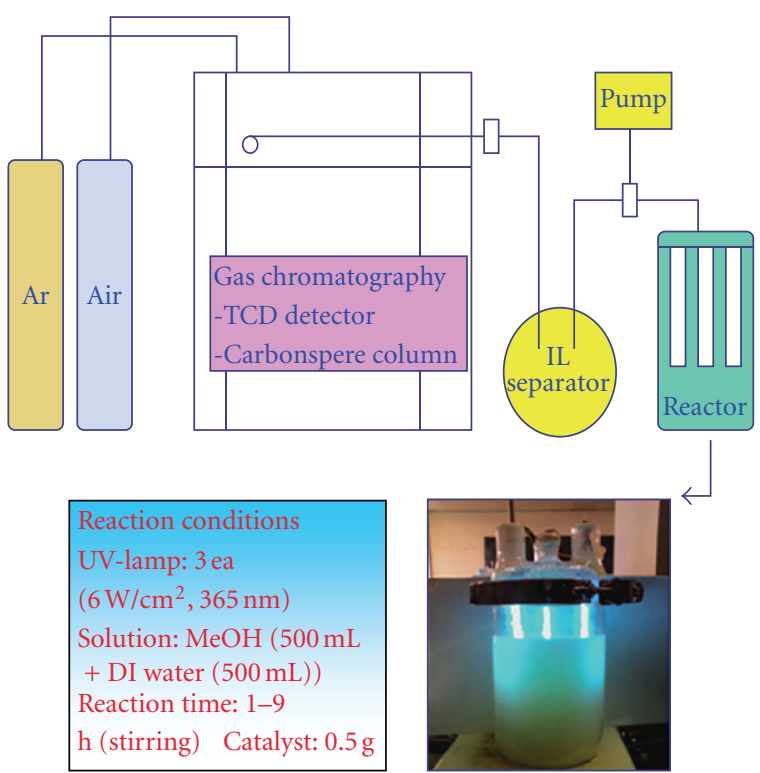

(a)

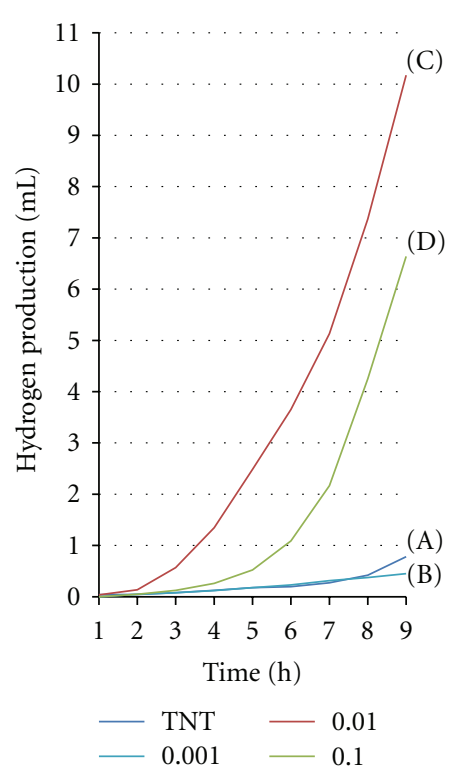

(b)

FIGURe 5: The evolution of $\mathrm{H}_{2}$ from methanol/water photosplitting over the TNT and Zn-TNT photocatalysts in a batch-type liquid photoreactor system. (a) Photoreactor system for hydrogen production from methanol aqueous solution and (b) hydrogen production from methanol aqueous solution according to the time on stream: (A) TNT, (B) $0.001 \mathrm{~mol} \% \mathrm{Zn}-\mathrm{TNT}$, (C) $0.01 \mathrm{~mol} \% \mathrm{Zn}-\mathrm{TNT}$, and (D) $0.1 \mathrm{~mol} \%$ Zn-TNT.

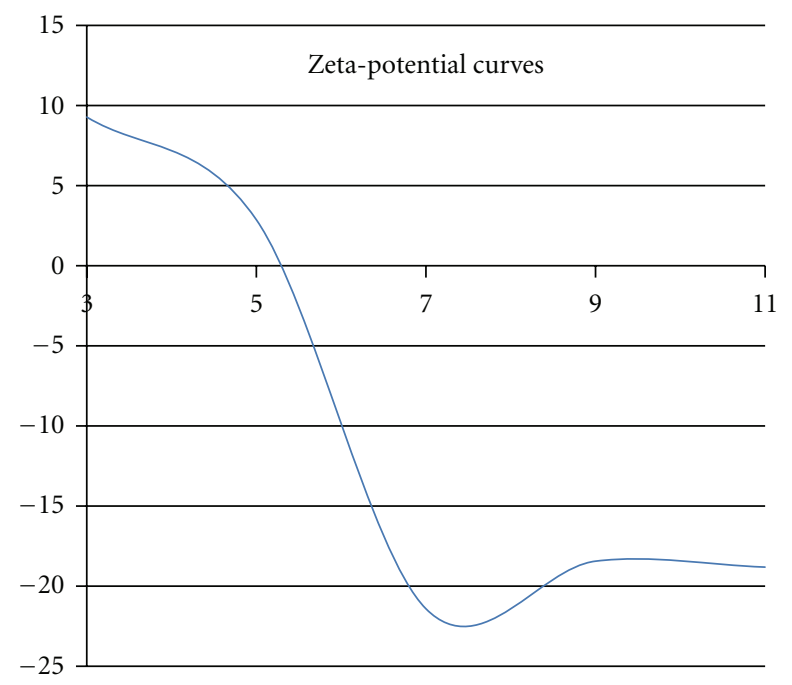

FIGURE 6: Zeta-potential curve for $0.01 \mathrm{~mol} \% \mathrm{Zn}$-TNT according to $\mathrm{pH}$.

to negative in alkali solution. For $0.01 \mathrm{~mol} \% \mathrm{Zn}$-TNT, the isoelectric point was at $\mathrm{pH} 5.3$ with large aggregation, but otherwise at $\mathrm{pH}=7.0$. The surface charge had the highest absolute value of $-21.41 \mathrm{mV}$, which indicated that the $0.01 \mathrm{~mol} \% \mathrm{Zn}$-TNT colloidal was stable $[27,28]$ having less aggregation. Table 3 summarize the zeta-potential values and aggregated diameter sizes for all samples at $\mathrm{pH}=7.0$ as determined by ELS. The Zn-TNT particles ranged from -18.86 to $-21.41 \mathrm{mV}$ on the surface and the particles were
TABLe 2: Zeta-potential values and aggregated diameter sizes for $0.01 \mathrm{~mol} \% \mathrm{Zn}$-TNT according to $\mathrm{pH}$, as determined by ELS.

\begin{tabular}{lcc}
\hline & Zeta potential $(\mathrm{mV})$ & ELS diameter $(\mathrm{nm})$ \\
\hline $\mathrm{pH}=3$ & 9.28 & 3641.8 \\
$\mathrm{pH}=5$ & 2.87 & 8385.4 \\
$\mathrm{pH}=7$ & -21.41 & 709.2 \\
$\mathrm{pH}=9$ & -18.44 & 687.5 \\
$\mathrm{pH}=11$ & -18.81 & 664.5 \\
\hline
\end{tabular}

TABLE 3: Zeta-potential values and aggregated diameter sizes for all samples at $\mathrm{pH}=7.0$, as determined by ELS.

\begin{tabular}{lcc}
\hline Samples at $\mathrm{pH}=7$ & Zeta potential $(\mathrm{mV})$ & ELS diameter $(\mathrm{nm})$ \\
\hline TNT & -18.44 & 468.2 \\
$0.001 \mathrm{~mol} \%$ Zn-TNT & -18.86 & 728.0 \\
$0.010 \mathrm{~mol} \%$ Zn-TNT & -21.41 & 709.2 \\
$0.100 \mathrm{~mol} \%$ Zn-TNT & -19.07 & 618.2 \\
\hline
\end{tabular}

suspended with high charge with the increase of the $\mathrm{Zn}$ gradient. The zeta-potential was maximized at $-21.41 \mathrm{mV}$ in the $0.01 \mathrm{~mol} \% \mathrm{Zn}$-TNT suspension. The zeta potential and mobility of the Zn-TNT particles were relatively high for electrophoretic display compared to those of TNT.

The absorption band of TNT and Zn-TNT for the tetrahedral symmetry of $\mathrm{Ti}^{4+}$ normally appeared at approximately 350 400 nm (Figure 7(a)). The maximum absorption bands in Zn-TNT were slightly shifted to a shorter wavelength than those of TNT but a broadened tail appeared in Zn-TNT. Bandgaps in semiconductor materials are 


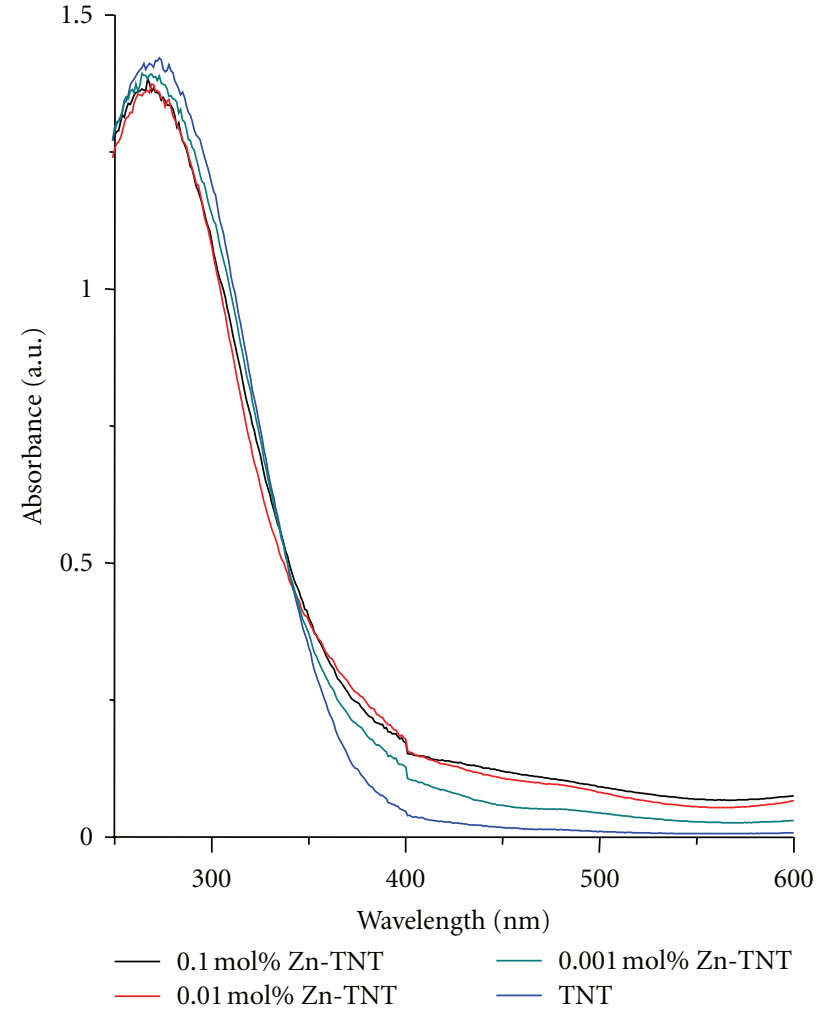

(a)

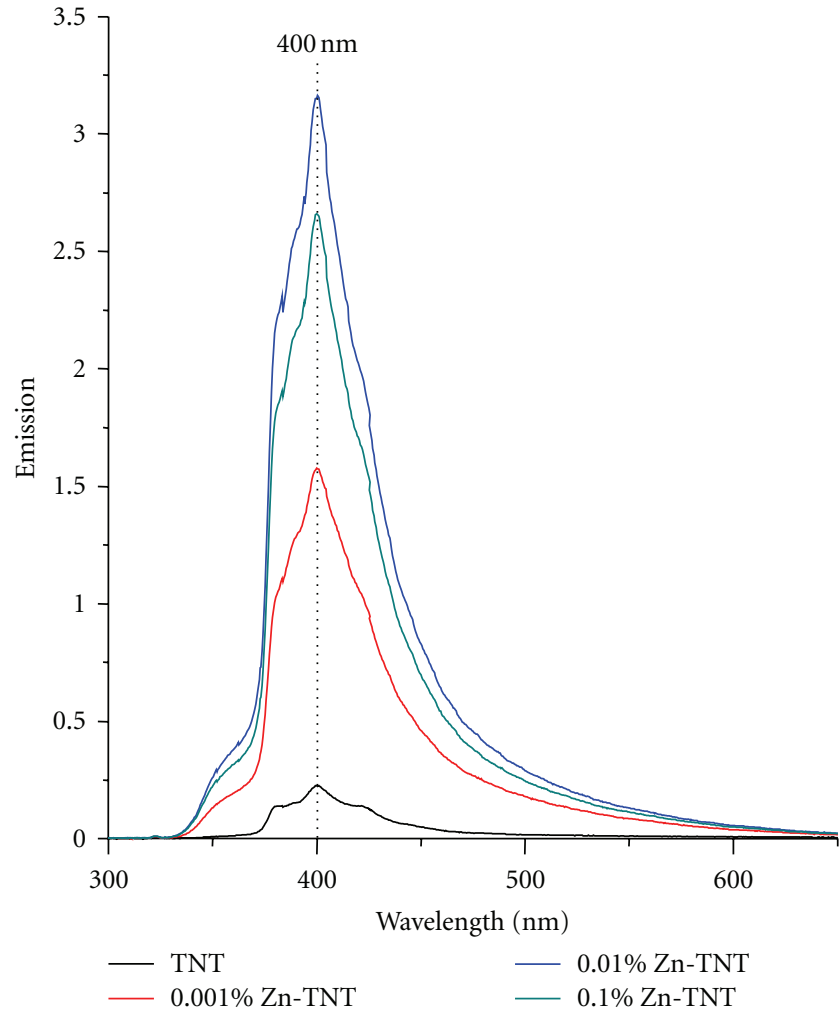

(b)

Figure 7: UV-visible and PL spectra of TNT and Zn-TNT: (a) UV-visible spectra of TNT and Zn-TNT and (b) photoluminescence (PL) spectra of TNT and Zn-TNT.

closely related to the wavelength range absorbed, where the bandgap decreases with increasing absorption wavelength. The bandgaps obtained by extrapolation based on the Tauc equation [29] in TNT and $0.01 \mathrm{~mol} \% \mathrm{Zn}$-TNT were about $3.54 \mathrm{eV}$ and $3.44 \mathrm{eV}$, respectively. A shorter bandgap eases the movement of excited electrons from the valence band to the conduction band on the surface, which occurs despite the weaker visible radiation. Otherwise, the recombination between electron and hole is faster for a smaller bandgap, which decreases the photocatalytic performance. Figure 7(b) presents the PL spectra of TNT and Zn-TNT. The PL curve indicates that the electrons in the valence band were transferred in an excited state to the conduction band and then stabilized by photoemission. In general, an increased number of emitted electrons resulting from the recombination between excited electrons and holes increases the PL intensity and thus decreases the photoactivity. Therefore, there is a strong relationship between PL intensity and photoactivity. However, in the presence of a metal that can capture excited electrons or exhibit conductivity, known as the relaxation process, the PL intensity decreases to a greater extent. In Figure 7(b), the PL curve of Zn-TNT was similar to that of TNT with an emission at $400 \mathrm{~nm}$. The PL intensity of Zn-TNT was larger and maximized in $0.01 \mathrm{~mol} \% \mathrm{Zn}$-TNT.

The utility of the CV results shown in Figure 8(a) is highly dependent on the analytic condition being studied, and it has to be redox active within the experimental potential window. It is desirable to display a reversible wave in order to provide the following information. The reversible reactions display a hysteresis of absolute potential between the reduction $\left(E_{\mathrm{pc}}\right)$ and oxidation $\left(E_{\mathrm{pa}}\right)$ peaks. Reversible reactions show a ratio of the peak currents passed at reduction $\left(i_{\mathrm{pc}}\right)$ and oxidation $\left(i_{\mathrm{pa}}\right)$ that is near unity $\left(1=i_{\mathrm{pa}} / i_{\mathrm{pc}}\right)$. When such reversible peaks are observed, thermodynamic information in the form of half-cell potential, $E_{1 / 2}^{0}\left(E_{\mathrm{pc}}+E_{\mathrm{pa}} / 2\right)$ can also be determined [30, 31]. In particular when, waves are semi-reversible, such as when $i_{\mathrm{pa}} / i_{\mathrm{pc}}$ is less than or greater than 1 , it can be possible to determine more information about the kinetic processes. In this study, the oxidation potentials were measured by means of $\mathrm{CV}$ in distilled water solutions of the $0.2 \mathrm{mM}$ complex using a pelletized sample as the working electrode, $\mathrm{Ag} / \mathrm{AgCl}$ as the reference electrode, and $0.1 \mathrm{M} \mathrm{KCl}$ as the supporting electrolyte. The electronic parameters for $\mathrm{CV}$ are listed in Table 4. The synthesized TNT and Zn-TNT exhibited the $\mathrm{Ti}(\mathrm{IV}) \rightarrow \mathrm{Ti}(\mathrm{III})$ redox process for a reversible reaction, and the absolute potentials between the reduction $\left(E_{\mathrm{pc}}\right)$ are seen at $-0.79,-0.43,-0.46$, and $-0.41 \mathrm{eV}$ in TNT, and $0.001 \mathrm{~mol} \%, 0.01 \mathrm{~mol} \%$, and $0.1 \mathrm{~mol} \% \mathrm{Zn}$-TNT samples, respectively.

Recently, some researchers have reported a useful equation that can be used to determine the energy levels of the highest occupied molecular orbital (HOMO) and the lowest unoccupied molecular orbital (LUMO) using CV [31]. The 


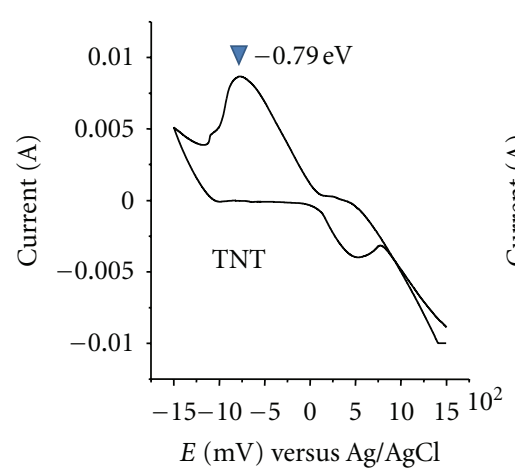

(A)

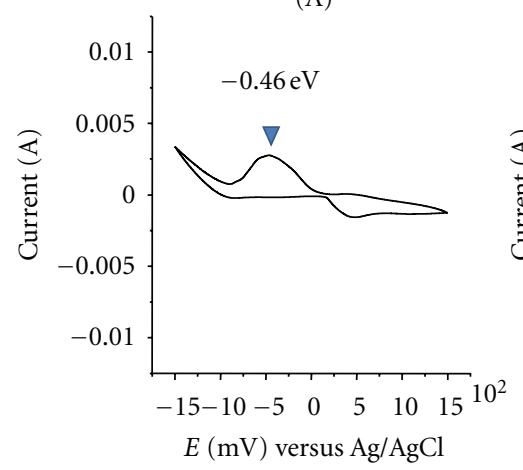

(C)

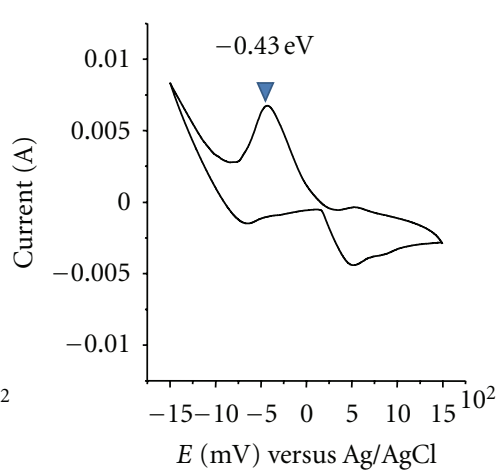

(B)

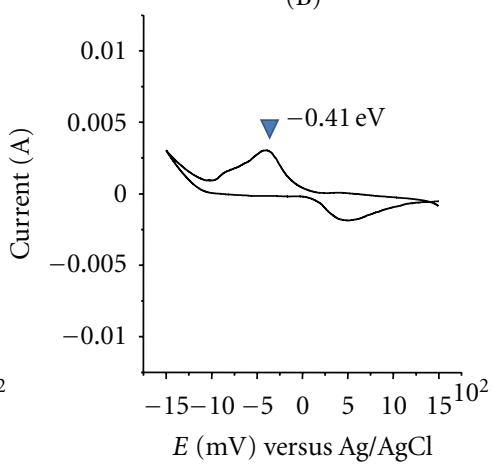

(D)

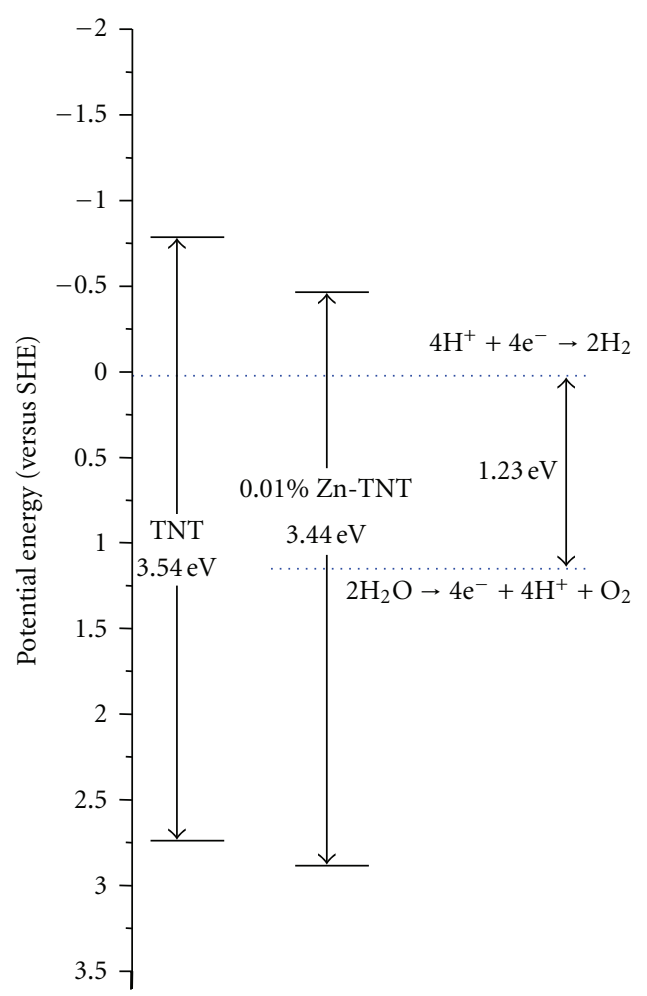

(b)

FIGURE 8: CV of TNT and Zn-TNT (a) and an expected potential energy diagram based on UV-visible spectra and CV (b): (A) TNT, (B) $0.001 \mathrm{~mol} \% \mathrm{Zn}-\mathrm{TNT}$, (C) $0.01 \mathrm{~mol} \% \mathrm{Zn}-\mathrm{TNT}$, and (D) $0.1 \mathrm{~mol} \% \mathrm{Zn}-\mathrm{TNT}$.

TABLE 4: Bandgap and HOMO-LUMO values based on CV and UV-visible spectroscopy.

\begin{tabular}{lcccc}
\hline eV & TNT & 0.001 mol\% Zn-TNT & 0.01 mol\% Zn-TNT & 0.1 mol\% Zn-TNT \\
\hline Ag/AgCl (LUMO) & -0.79 & -0.43 & -0.46 & -0.41 \\
HOMO & 2.75 & 3.02 & 2.98 & 2.96 \\
Bandgap & 3.54 & 3.45 & 3.44 & 3.37 \\
\hline
\end{tabular}

results of the CV curve and UV-visible spectra are presented in Table 4, and Figure 8(b) is plotted based on these data. The bandgap of Zn-TNT was shorter than that of pure TNT, particularly $0.01 \mathrm{~mol} \% \mathrm{Zn}$-TNT, and its valence and conduction bands were at lower energy levels than those of TNT. This indicated that the energy level of the electrons excited from the valence band during photocatalysis was further elevated, which increased the hole effect at the valence band to a much greater extent than that in TNT. These phenomena consequently increased the evolution of $\mathrm{OH}$ radicals formed from the electrons and holes, and the resulting increase in the degradation rate of methanol and water eventually enhanced the photocatalytic performance. Therefore, the photocatalytic activity was enhanced over Zn-TNT.

\section{Conclusions}

Zn-TNT was synthesized using Zn-TNP loaded with three different molar ratios on nanosized $\mathrm{TiO}_{2}$. As shown by
TEM observation, the morphology of Zn-TNT was a regular tube shape with a length of $1 \sim 2 \mu \mathrm{m}$ and width of 70 $100 \mathrm{~nm}$. The UV-visible spectra and CV results revealed that the bandgap in TNT and $0.01 \mathrm{~mol} \% \mathrm{Zn}$-TNT was about 3.54 and $3.44 \mathrm{eV}$, and the LUMO energy levels were calculated as -0.79 and $-0.43 \mathrm{eV}$, respectively. The zeta potential and mobility of the Zn-TNT particles were relatively high for electrophoretic display, compared to those of TNT. The zeta-potential was maximized at $-21.41 \mathrm{mV}$ in the $0.01 \mathrm{~mol} \% \mathrm{Zn}$-TNT suspension. These spectroscopic properties facilitated the collection of a significant amount of $\mathrm{H}_{2}$ gas $(10.2 \mathrm{~mL})$ over $0.5 \mathrm{~g}$ of the $0.01 \mathrm{~mol} \% \mathrm{Zn}-\mathrm{TNT}$ catalyst.

\section{Acknowledgment}

This research was supported by a Yeungnam University research grant, no. 211-A-380-136, and the authors are very grateful for this support. 


\section{References}

[1] H.-W. Wang, H.-W. Chung, H.-T. Teng, and G. Cao, "Generation of hydrogen from aluminum and water-effect of metal oxide nanocrystals and water quality," International Journal of Hydrogen Energy, vol. 36, pp. 15136-15144, 2011.

[2] Y. Liu, L. Guo, W. Yan, and H. Liu, "A composite visiblelight photocatalyst for hydrogen production," Journal of Power Sources, vol. 159, no. 2, pp. 1300-1304, 2006.

[3] M. Antoniadou, P. Bouras, N. Strataki, and P. Lianos, "Hydrogen and electricity generation by photoelectrochemical decomposition of ethanol over nanocrystalline titania," International Journal of Hydrogen Energy, vol. 33, no. 19, pp. 50455051, 2008.

[4] N.-L. Wu, M.-S. Lee, Z.-J. Pon, and J.-Z. Hsu, "Effect of calcination atmosphere on $\mathrm{TiO}_{2}$ photocatalysis in hydrogen production from methanol/water solution," Journal of Photochemistry and Photobiology A, vol. 163, pp. 277-280, 2004.

[5] M. I. Badawy, M. Y. Ghaly, and M. E. M. Ali, "Photocatalytic hydrogen production over nanostructured mesoporous titania from olive mill wastewater," Desalination, vol. 267, no. 2-3, pp. 250-255, 2011.

[6] S. Xu, J. Ng, X. Zhang, H. Bai, and D. D. Sun, "Fabrication and comparison of highly efficient $\mathrm{Cu}$ incorporated $\mathrm{TiO}_{2}$ photocatalyst for hydrogen generation from water," International Journal of Hydrogen Energy, vol. 35, no. 11, pp. 5254-5261, 2010.

[7] R. Dholam, N. Patel, and A. Miotello, "Efficient $\mathrm{H}_{2}$ production by water-splitting using indium-tin-oxide/V-doped $\mathrm{TiO}_{2}$ multilayer thin film photocatalyst," International Journal of Hydrogen Energy, vol. 36, no. 11, pp. 6519-6528, 2011.

[8] T. Puangpetch, T. Sreethawong, and S. Chavadej, "Hydrogen production over metal-loaded mesoporous-assembled $\mathrm{SrTiO}_{3}$ nanocrystal photocatalysts: effects of metal type and loading," International Journal of Hydrogen Energy, vol. 35, no. 13, pp. 6531-6540, 2010.

[9] S. Onsuratoom, S. Chavadej, and T. Sreethawong, "Hydrogen production from water splitting under UV light irradiation over Ag-loaded mesoporous-assembled $\mathrm{TiO}_{2}-\mathrm{ZrO}_{2}$ mixed oxide nanocrystal photocatalysts," International Journal of $\mathrm{Hy}$ drogen Energy, vol. 36, no. 9, pp. 5246-5261, 2011.

[10] R. Sasikala, A. Shirole, V. Sudarsan et al., "Highly dispersed phase of $\mathrm{SnO}_{2}$ on $\mathrm{TiO}_{2}$ nanoparticles synthesized by polyolmediated route: photocatalytic activity for hydrogen generation," International Journal of Hydrogen Energy, vol. 34, no. 9, pp. 3621-3630, 2009.

[11] M.-S. Park and M. Kang, "The preparation of the anatase and rutile forms of $\mathrm{Ag}-\mathrm{TiO}_{2}$ and hydrogen production from methanol/water decomposition," Materials Letters, vol. 62, pp. 183-187, 2008.

[12] B. S. Kwak, J. Chae, J. Kim, and M. Kang, "Enhanced hydrogen production from methanol/water photo-splitting in $\mathrm{TiO}_{2}$ including Pd component," Bulletin of the Korean Chemical Society, vol. 30, pp. 1047-1053, 2009.

[13] X.-J. Zheng, L.-F. Wei, Z.-H. Zhang et al., "Research on photocatalytic $\mathrm{H}_{2}$ production from acetic acid solution by $\mathrm{Pt} / \mathrm{TiO}_{2}$ nanoparticles under UV irradiation," International Journal of Hydrogen Energy, vol. 34, no. 22, pp. 9033-9041, 2009.

[14] J. Chae, J. Lee, J. H. Jeong, and M. Kang, "Hydrogen pro- duction from photo splitting of water using the Ga-incorporated $\mathrm{TiO}_{2}$ s prepared by a solvothermal method and their characteristics," Bulletin of the Korean Chemical Society, vol. 30, p. 302, 2009.
[15] S. Xu, J. Ng, A. J. Du, J. Liu, and D. D. Sun, "Highly efficient $\mathrm{TiO}_{2}$ nanotube photocatalyst for simultaneous hydrogen production and copper removal from water," International Journal of Hydrogen Energy, vol. 36, no. 11, pp. 6538-6545, 2011.

[16] L. X. Sang, Z. Y. Zhang, G. M. Bai, C. X. Du, and C. F. Ma, "A photoelectrochemical investigation of the hydrogen-evolving doped $\mathrm{TiO}_{2}$ nanotube arrays electrode," International Journal of Hydrogen Energy, vol. 37, pp. 854-859, 2012.

[17] L. X. Sang, Z. Y. Zhang, and C. F. Ma, "Photoelectrical and charge transfer properties of hydrogen-evolving $\mathrm{TiO}_{2}$ nanotube arrays electrodes annealed in different gases," International Journal of Hydrogen Energy, vol. 36, no. 8, pp. 47324738, 2011.

[18] H.-H. Ou and S.-L. Lo, "Review of titania nanotubes synthesized via the hydrothermal treatment: fabrication, modification, and application," Separation and Purification Technology, vol. 58, no. 1, pp. 179-191, 2007.

[19] J. Skvarla, "Evaluation of mutual interactions in binary mineral suspensions by means of electrophoretic light scattering (ELS)," International Journal of Mineral Processing, vol. 48, pp. 95-109, 1996.

[20] C. Li, J. Yuan, B. Han, L. Jiang, and W. Shangguan, “ $\mathrm{TiO}_{2}$ nanotubes incorporated with CdS for photocatalytic hydrogen production from splitting water under visible light irradiation," International Journal of Hydrogen Energy, vol. 35, no. 13, pp. 7073-7079, 2010.

[21] S. A. Setiadi, "Photocatalytic hydrogen generation from glycerol and water using Pt loaded $\mathrm{N}$-doped $\mathrm{TiO}_{2}$ nanotube," International Journal of Engineering and Technology, vol. 11, no. 3, pp. 91-95, 2011.

[22] W. Stefaniak, J. Goworek, and B. Biliński, "Pore size analysis by nitrogen adsorption and thermal desorption," Colloids and Surfaces A, vol. 214, no. 1-3, pp. 231-237, 2003.

[23] S. Onsuratoom, S. Chavadej, and T. Sreethawong, "Hydrogen production from water splitting under UV light irradiation over Ag-loaded mesoporous-assembled $\mathrm{TiO}_{2}-\mathrm{ZrO}_{2}$ mixed oxide nanocrystal photocatalysts," International Journal of Hydrogen Energy, vol. 36, no. 9, pp. 5246-5261, 2011.

[24] M. Iza, S. Woerly, C. Danumah, S. Kaliaguine, and M. Bousmina, "Determination of pore size distribution for mesoporous materials and polymeric gels by means of DSC measurements: thermoporometry," Polymer, vol. 41, no. 15, pp. 5885-5893, 2000.

[25] H. Y. Zhu and G. Q. Lu, "Estimating pore size distribution from the differential curves of comparison plots," Studies in Surface Science and Catalysis, vol. 128, pp. 243-250, 2000.

[26] A. C. Mitropoulos, “The Kelvin equation," Journal of Colloid and Interface Science, vol. 317, no. 2, pp. 643-648, 2008.

[27] D. L. Liao, G. S. Wu, and B. Q. Liao, "Zeta potential of shapecontrolled $\mathrm{TiO}_{2}$ nanoparticles with surfactants," Colloids and Surfaces A, vol. 348, no. 1-3, pp. 270-275, 2009.

[28] K. Maeda, M. Eguchi, W. J. Youngblood, and T. E. Mallouk, "Niobium oxide nanoscrolls as building blocks for dyesensitized hydrogen production from water under visible light irradiation," Chemistry of Materials, vol. 20, no. 21, pp. 67706778, 2008.

[29] A. W. Burton, K. Ong, T. Rea, and I. Y. Chan, "On the estimation of average crystallite size of zeolites from the Scherrer equation: a critical evaluation of its application to zeolites with one-dimensional pore systems," Microporous and Mesoporous Materials, vol. 117, pp. 75-90, 2009.

[30] K. B. Oldham and J. C. Myland, "Modelling cyclic voltammetry without digital simulation," Electrochimica Acta, vol. 56, no. 28 , pp. 10612-10625, 2011. 
[31] M. Wang, D.-J. Guo, and H.-L. Li, "High activity of novel $\mathrm{Pd} / \mathrm{TiO}_{2}$ nanotube catalysts for methanol electro-oxidation," Journal of Solid State Chemistry, vol. 178, no. 6, pp. 1996-2000, 2005. 


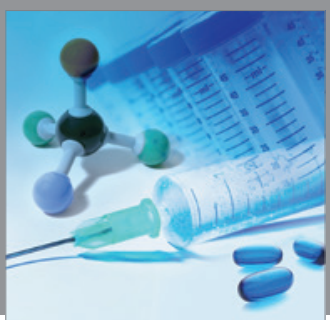

International Journal of

Medicinal Chemistry

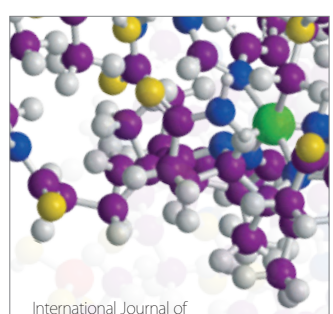

Carbohydrate Chemistry

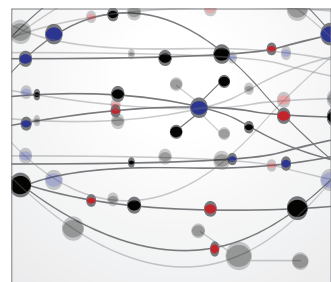

The Scientific World Journal
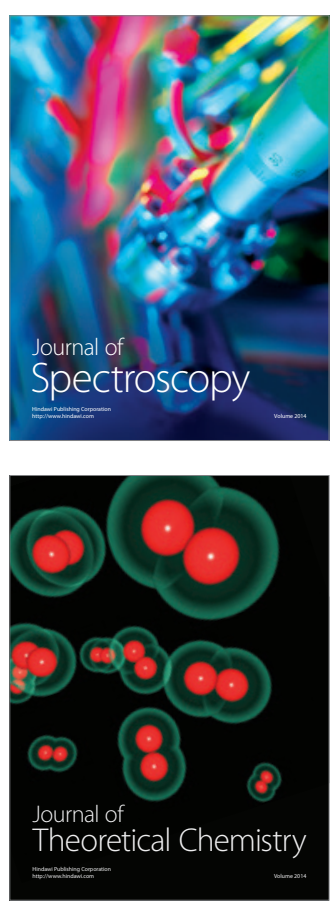
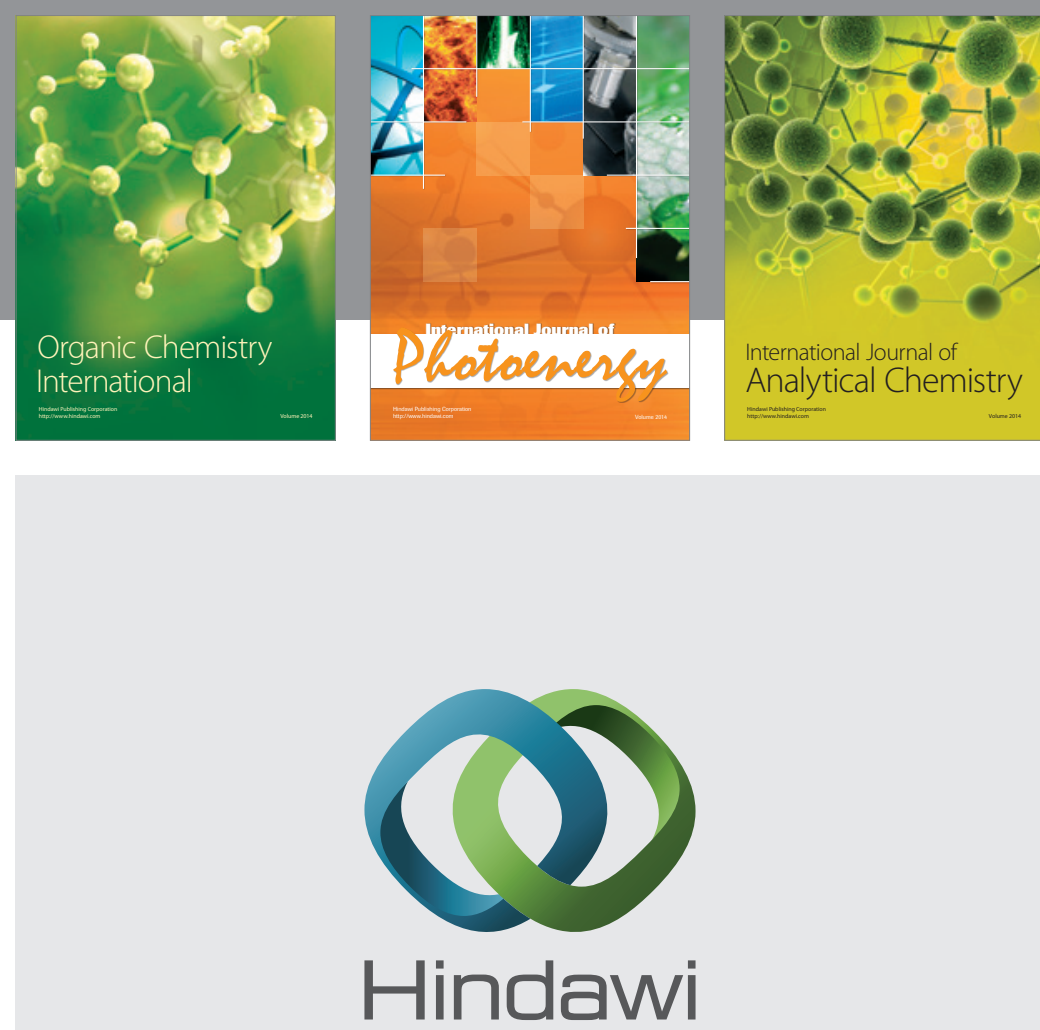

Submit your manuscripts at

http://www.hindawi.com
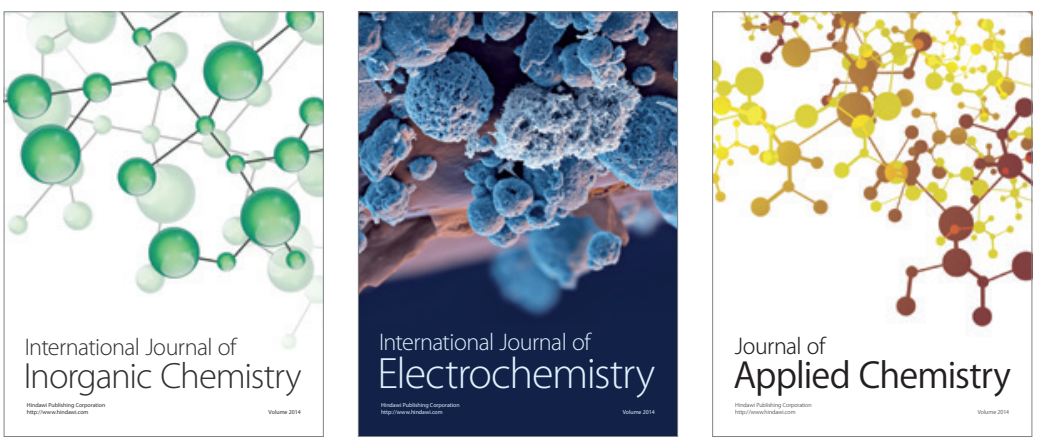

Journal of

Applied Chemistry
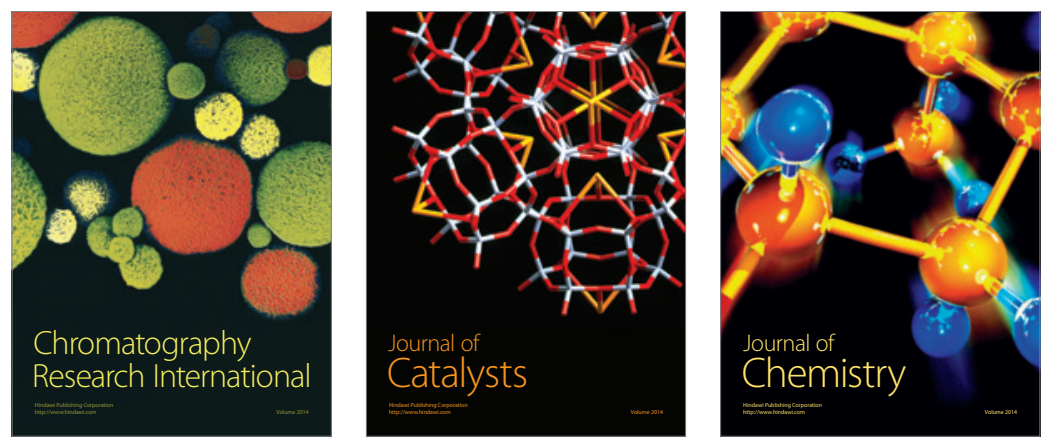
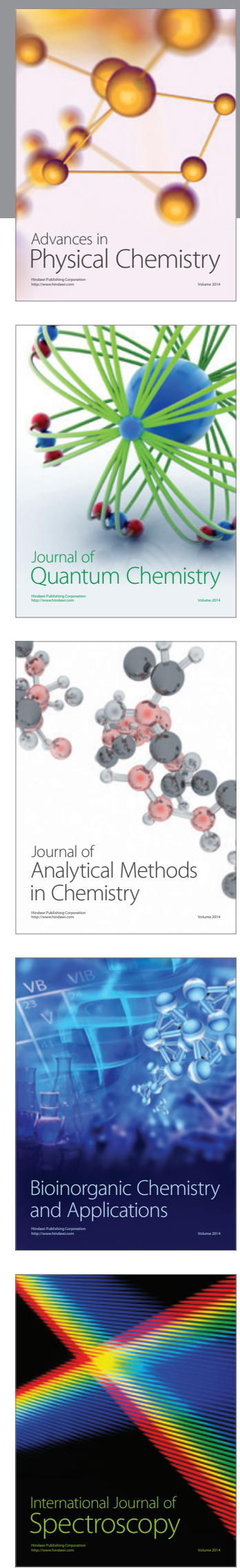